\title{
Atomic Layer Deposition of Lithium Tantalate Solid-State Electrolytes
}

\author{
Jian Liu, ${ }^{\dagger}$ Mohammad N. Banis, ${ }^{\dagger}$ Xifei Li, ${ }^{\dagger}$ Andrew Lushington, ${ }^{\dagger}$ Mei Cai, ${ }^{\ddagger}$ Ruying Li, ${ }^{\dagger}$ Tsun-Kong Sham, ${ }^{\S}$ \\ and Xueliang Sun ${ }^{\dagger} \dagger$
}

${ }^{\dagger}$ Department of Mechanical and Materials Engineering, University of Western Ontario, London, ON, Canada N6A 5B9

${ }^{\ddagger}$ General Motors R\&D Center, Warren, Michigan 48090-9055, United States

${ }^{\S}$ Department of Chemistry, University of Western Ontario, London, ON, Canada N6A 5B7

\section{Supporting Information}
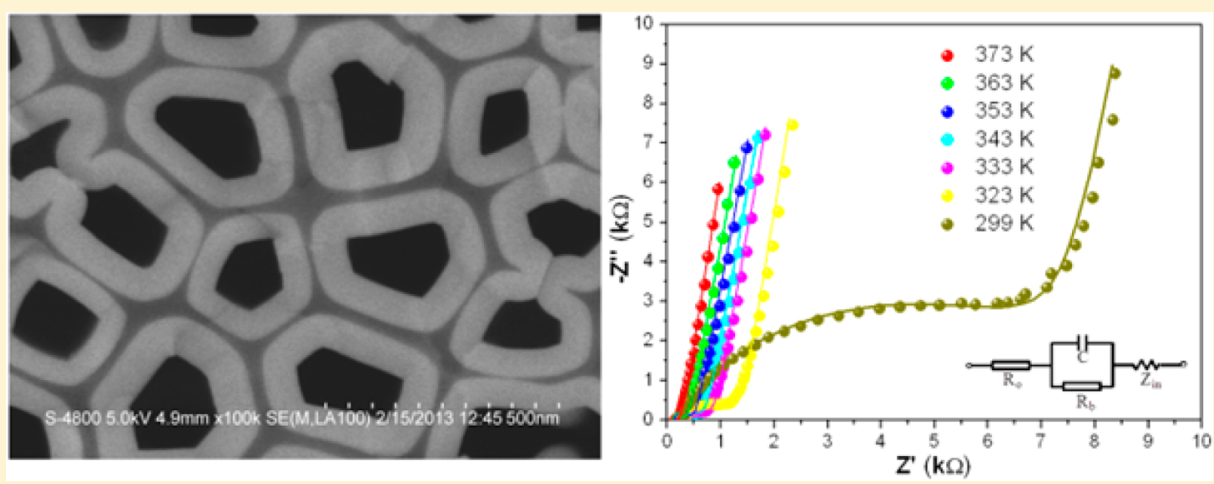

ABSTRACT: 3D all-solid-state microbatteries are promising onboard power systems for autonomous devices. The fabrication of 3D microbatteries needs deposition of active materials, especially solid-state electrolytes, as conformal and pinhole free thin films in $3 \mathrm{D}$ architectures, which has proven very difficult for conventional deposition techniques, such as chemical vapor deposition and physical vapor deposition. Herein, we report an alternative technique, atomic layer deposition (ALD), for achieving ideal solid-state electrolyte thin films for 3D microbatteries. Lithium tantalate solid-state electrolytes, with well-controlled film composition and film thickness, were grown by $\mathrm{ALD}$ at $225{ }^{\circ} \mathrm{C}$ using subcycle combination of $1 \times \mathrm{Li}_{2} \mathrm{O}+n \times \mathrm{Ta}_{2} \mathrm{O}_{5}(1 \leq n \leq$ 10). The film composition was tunable by varying $\mathrm{Ta}_{2} \mathrm{O}_{5}$ subcycles $(n)$, whereas the film thickness displayed a linear relationship with ALD cycle number, due to the self-limiting nature of the ALD process. Furthermore, the lithium tantalate thin films showed excellent uniformity and conformity in 3D anodic aluminum oxide template. Moreover, impedance testing showed that the lithium tantalate thin film exhibited a lithium ion conductivity of $2 \times 10^{-8} \mathrm{~S} / \mathrm{cm}$ at $299 \mathrm{~K}$. The lithium tantalate thin films by $\mathrm{ALD}$, featured with well-controlled film thickness and composition, excellent step coverage, and moderate ionic conductivity at room temperature, would be promising solid-state electrolytes for $3 \mathrm{D}$ microbatteries.

\section{INTRODUCTION}

Microelectronic devices are becoming increasingly incorporated into our daily activities. A great deal of effort has been devoted to developing autonomous devices, such as medical implants, self-powered integrated circuits, and microelectromechanical systems, which need be driven by an on-board power supply system. ${ }^{1,2}$ Lithium-ion batteries (LIBs) are a preferable energy medium for these types of applications, due to their ability to deliver high energy density. ${ }^{2}$ In particular, all-solid-state LIBs have drawn great attention from various industries, since they can permit greater flexibility in the design of batteries, provide improved intrinsic safety due to the absence of liquid electrolytes, and facilitate miniaturization of microelectronic devices. ${ }^{1-3}$ During the past decade, research in the field of allsolid-state LIBs has been primarily focused on two-dimensional (2D) thin film batteries. ${ }^{4,5}$ However, it is becoming difficult for $2 \mathrm{D}$ thin film batteries to meet the elevated power consumption demand in modern microelectronic devices due to their limited energy density per unit area. ${ }^{2}$ One effective strategy to increase the capacity per unit area $\left(\mu \mathrm{A} \mathrm{h} \mathrm{cm}{ }^{-2}\right)$ of all-solid-sate LIBs is developing three-dimensional (3D) microbatteries instead of 2D thin film batteries. 3D microbatteries can offer significantly increased specific surface area of active materials in the same areal footprint as $2 \mathrm{D}$ thin film batteries and maintain short path lengths for the diffusion of lithium ion, thereby rendering greatly enhanced battery capacity per unit area.,3 Given the advantages and demand of 3D microbatteries, various concepts for their design have been proposed..$^{1-3,6-9}$ However, it is still challenging to fabricate real 3D microbatteries, partly due to the great limitations of conventional deposition techniques

Received: June 26, 2013

Revised: September 5, 2013

Published: September 6, 2013 
employed in the fabrication of $2 \mathrm{D}$ thin film batteries, such as physical vapor deposition (PVD), chemical vapor deposition (CVD), and electrochemical deposition. One of the most difficult, but crucial, steps in the fabrication of $3 \mathrm{D}$ microbatteries is the deposition of conformal and pinhole-free thin films onto $3 \mathrm{D}$ structures. The thin films required in $3 \mathrm{D}$ microbatteries must be perfect and free of cracks or pinholes, which will result in short circuits and failure of batteries. It has been realized that the key to achieving as-desired thin films in $3 \mathrm{D}$ architectures is the use of a deposition technique that is inherently self-limiting. ${ }^{8,10}$

Atomic layer deposition (ALD) has been known as a thin film technique being capable of depositing high-quality films in 3D structures. ${ }^{11}$ Unlike other film deposition methods, such as PVD or CVD, ALD employs self-limiting surface reactions via alternating, saturated precursor doses. ${ }^{12,13}$ As a consequence, ALD provides exquisite control over the thickness of thin films, and the thin films deposited by ALD have excellent conformality and uniformity, even in 3D substrates with aspect ratio in excess of $1000 .^{14}$ These unique features make ALD a suitable technique for fabricating 3D microbatteries, and its potential has been demonstrated recently. ${ }^{15-17}$ For example, anatase $\mathrm{TiO}_{2}$ thin film with $17 \mathrm{~nm}$ thickness was deposited by ALD directly on aligned aluminum nanorods, which served as current collectors. ${ }^{15}$ The $3 \mathrm{D} \mathrm{TiO}_{2}$ nanoelectrode exhibited a capacity 10 times higher than traditional $2 \mathrm{D} \mathrm{TiO}_{2}$ electrode in the same areal footprint and showed excellent rate capability and stability in 50 charge-discharge cycling. $\mathrm{V}_{2} \mathrm{O}_{5}$ thin films were deposited using ALD on micropillars coated with TMV/ $\mathrm{Ni}$, forming hierarchical 3D electrodes. ${ }^{17}$ The conformal $\mathrm{V}_{2} \mathrm{O}_{5}$ thin films on the 3D micropillar electrodes enabled much higher energy density and faster charge-discharge rate than those on a planar substrate. Even though no real 3D microbatteries have been manufactured by ALD, given the aforementioned exclusive advantages, it is expected that ALD will play an important role in fabricating $3 \mathrm{D}$ microbatteries in the near future.

In recent years, ALD has been widely applied in conventional LIBs, either to directly prepare active materials (such as $\mathrm{SnO}_{2}$, $\left.\mathrm{Li}_{4} \mathrm{Ti}_{5} \mathrm{O}_{12}, \mathrm{~V}_{2} \mathrm{O}_{5}\right)^{18-22}$ or to coat the anode or cathode electrodes with metal oxides (such as $\mathrm{Al}_{2} \mathrm{O}_{3}, \mathrm{ZrO}_{2}, \mathrm{ZnO}$ ) aiming at improving their performance. ${ }^{23-32}$ However, the application of ALD technique in 3D microbatteries is still rare. Advancement in the field of 3D microbatteries prepared by ALD is highly reliant on the development of battery materials, i.e., anodes, solid-state electrolytes, and cathodes. ${ }^{33,34}$ Some ALD-derived materials (mainly metal oxide such as $\mathrm{TiO}_{2}, \mathrm{SnO}_{2}$, $\mathrm{V}_{2} \mathrm{O}_{5}$ ) have been directly adopted as anodes or cathodes in $3 \mathrm{D}$ microbatteries. ${ }^{33,34}$ However, there have been very few reports on the synthesis of solid-state electrolytes by ALD. ${ }^{35-41}$ It was not until 2009 that research relevant to solid-state electrolytes deposited by ALD started to emerge, when the ALD process for $\mathrm{Li}_{2} \mathrm{O}$ was first investigated. ${ }^{35}$ Aaltonen et al. ${ }^{36}$ applied ALD to grow lithium lanthanum titanate (LLT) electrolytes at 225 ${ }^{\circ} \mathrm{C}$ by combining subcycles of $\mathrm{TiO}_{2}\left(\mathrm{TiCl}_{4}-\mathrm{H}_{2} \mathrm{O}\right), \mathrm{La}_{2} \mathrm{O}_{3}$ ( $\left.\mathrm{La}(\text { thd })_{3}-\mathrm{O}_{3}\right)$, and $\mathrm{Li}_{2} \mathrm{O}\left(\mathrm{LiO}^{t} \mathrm{Bu}-\mathrm{H}_{2} \mathrm{O}\right)$. The LLT thin film deposited at saturation conditions had a composition of $\mathrm{Li}_{0.32} \mathrm{La}_{0.30} \mathrm{TiO}_{z}$, with amorphous structure. The LLT thin film was crystallized after annealing at $800{ }^{\circ} \mathrm{C}$ in oxygen for $3 \mathrm{~h}$. Later on, $\mathrm{Li}_{2} \mathrm{O}-\mathrm{Al}_{2} \mathrm{O}_{3}$ thin films were fabricated by the same group using $\mathrm{ALD}$ of $\mathrm{Li}_{2} \mathrm{O}\left(\mathrm{LiO}^{t} \mathrm{Bu}-\mathrm{H}_{2} \mathrm{O}\right)$ and $\mathrm{Al}_{2} \mathrm{O}_{3}$ (TMA$\left.\mathrm{O}_{3}\right){ }^{37}$ The thickness of the $\mathrm{Li}_{2} \mathrm{O}-\mathrm{Al}_{2} \mathrm{O}_{3}$ thin film was found to depend on ALD cycles linearly, yielding a growth rate of $2.8 \AA$ // cycle. Hämäläinen et al. ${ }^{38,39}$ described the deposition of lithium phosphate and lithium silicate thin films by ALD. The lithium phosphate was deposited between 225 and $350{ }^{\circ} \mathrm{C}$ using trimethyl phosphate and either of LiHMDS or $\mathrm{LiO}^{t} \mathrm{Bu}$, and the lithium silicate was grown in a temperature range of 150-400 ${ }^{\circ} \mathrm{C}$ from LiHMDS and $\mathrm{O}_{3}$. In both cases, the growth rate and composition of the thin films were dependent on deposition temperature. Furthermore, $\mathrm{Li}_{3} \mathrm{~N}$ was deposited by ALD from LiHMDS and $\mathrm{NH}_{3}$ at $167^{\circ} \mathrm{C}$, showing a growth rate of $0.95 \AA$ // cycle. $^{40}$ Even though progress on ALD synthesis of solid-state electrolytes has been made, investigation on their lithium-ion conductivity was seldom conducted. Only Aaltonen et al. ${ }^{37}$ presented a lithium-ion conductivity of $1 \times 10^{-7} \mathrm{~S} / \mathrm{cm}$ (at 300 ${ }^{\circ} \mathrm{C}$ ) for $\mathrm{Li}_{2} \mathrm{O}-\mathrm{Al}_{2} \mathrm{O}_{3}$ thin film, which had been annealed at 700 ${ }^{\circ} \mathrm{C}$ for $5 \mathrm{~h}$. Unfortunately, the high operating temperature and postannealing requirement seriously hinder application of the $\mathrm{Li}_{2} \mathrm{O}-\mathrm{Al}_{2} \mathrm{O}_{3}$ thin film. The postannealing process increases the risk of cracking in solid-state electrolytes, leading to short circuits and failure of $3 \mathrm{D}$ microbatteries. Therefore, it is essential that the solid-state electrolyte thin films are prepared in a "gentle" manner to avoid cracking.

To fulfill the objective above, lithium tantalate was selected as the solid-state electrolyte to be deposited by ALD in this work. Lithium tantalate has the following advantages: (1) Being lithium-ion conductive with amorphous structure. Previous work has found that amorphous phase of lithium tantalate rather than crystalline one was conductive of lithium ions. ${ }^{42,43}$ The ALD-deposited lithium tantalate would show a disordered structure due to the low deposition temperature $\left(225^{\circ} \mathrm{C}\right)$ used herein. ${ }^{35-39}$ It was expected that the lithium tantalate grown by ALD could be a lithium-ion conductor at the as-deposited condition, saving post-treatment process and avoiding possible cracking of thin films during this process. (2) Displaying acceptable lithium-ion conductivity $\left(10^{-5}-10^{-8} \mathrm{~S} / \mathrm{cm}\right)$. (3) Negligible electronic conductivity at room temperature. ${ }^{42,43}$ In summary, this work realized the deposition of lithium tantalate thin films by ALD technique, for the first time. The synthesized lithium tantalate thin films were featured with not only precisely controlled film thickness, but well-tuned film composition. Most importantly, the lithium tantalate thin films by ALD, at the as-deposited state, exhibited moderate lithium-ion conductivity at room temperature, with no requirement of further treatments. Furthermore, the ALD approach reported herein could achieve uniform and conformal lithium tantalate thin films in a $3 \mathrm{D}$ architecture. It is believed that the lithium tantalate thin films deposited by ALD would have great potential as solid-state electrolytes in $3 \mathrm{D}$ microbatteries.

\section{EXPERIMENTAL SECTION}

All lithium tantalate thin films were deposited at $225{ }^{\circ} \mathrm{C}$ in a Savannah 100 ALD system (Cambridge Nanotech Inc.) by combining ALD subcycles of $\mathrm{Li}_{2} \mathrm{O}$ and $\mathrm{Ta}_{2} \mathrm{O}_{5}$. The $\mathrm{Li}_{2} \mathrm{O}$ subcycle consisted of alternating pulses of lithium tert-butoxide ( $\mathrm{LiO}{ }^{t} \mathrm{Bu},\left(\mathrm{CH}_{3}\right)_{3} \mathrm{COLi}$ ) and $\mathrm{H}_{2} \mathrm{O}$, while the $\mathrm{Ta}_{2} \mathrm{O}_{5}$ subcycle consisted of alternating pulses of tantalum $(\mathrm{V})$ ethoxide $\left(\mathrm{Ta}(\mathrm{OEt})_{5}, \mathrm{Ta}\left(\mathrm{OC}_{2} \mathrm{H}_{5}\right)_{5}\right)$ and $\mathrm{H}_{2} \mathrm{O}$. The source temperatures for $\mathrm{LiO}^{t} \mathrm{Bu}, \mathrm{Ta}(\mathrm{OEt})_{5}$, and $\mathrm{H}_{2} \mathrm{O}$ were 170,190 , and $23{ }^{\circ} \mathrm{C}$, respectively. The system pipelines were heated to $190{ }^{\circ} \mathrm{C}$ in order to prevent condensation of the precursors. The pulse times of $\mathrm{LiO}^{t} \mathrm{Bu}$ and $\mathrm{Ta}(\mathrm{OEt})_{5}$ were varied from 0.2 to $1.5 \mathrm{~s}$, while the pulse time of $\mathrm{H}_{2} \mathrm{O}$ remained at $1 \mathrm{~s}$. All precursor pulses were separated by a $10 \mathrm{~s}$ nitrogen purge. One ALD cycle 
was executed using a pulsing sequence of $1 \times\left[\mathrm{LiO}^{t} \mathrm{Bu}(0.2-1.5\right.$ s)-purge $(10 \mathrm{~s})-\mathrm{H}_{2} \mathrm{O}(1 \mathrm{~s})$-purge $\left.(10 \mathrm{~s})\right]-n \times\left[\mathrm{Ta}(\mathrm{OEt})_{5}\right.$ $(0.2-1.5 \mathrm{~s})$-purge $(10 \mathrm{~s})-\mathrm{H}_{2} \mathrm{O}(1 \mathrm{~s})$-purge $(10 \mathrm{~s})$ ], which was expressed as $1 \times \mathrm{Li}_{2} \mathrm{O}+n \times \mathrm{Ta}_{2} \mathrm{O}_{5}(1 \leq n \leq 10)$ in brief. All lithium tantalate thin films were deposited on planar $\mathrm{Si}$ (100) and glass substrates. Anodic aluminum oxide (AAO, Anodisc 13, Whatman) template with aspect ratio of $\sim 300$ was chosen as a $3 \mathrm{D}$ substrate. All characterizations were carried out on the $\mathrm{Si}$ (100) substrate except otherwise noted.

After ALD coatings, the Si (100) substrate was cut into small pieces. One piece of $\mathrm{Si}(100)$ with fresh surface was chosen and pasted onto a vertical SEM holder using carbon slurry. The thicknesses of the lithium tantalate thin films were measured from the fresh cross sections of the $\mathrm{Si}$ (100) using fieldemission scanning electron microscopy (SEM, Hitachi-4800). The thicknesses of the thin films were obtained by taking average of 10 values measured at different locations of each sample. The compositions of the lithium tantalate thin films were analyzed by using X-ray photoelectron spectroscopy (XPS) using Kratos Axis Ultra Al (alpha) spectrometer. The phases of the lithium tantalate thin films on the glass substrate were identified using micro-X-ray diffraction (XRD, Bruker D8, Co $\mathrm{K} \alpha$ source, $\lambda=1.7892 \AA$ ). The Ta $\mathrm{L}_{3}$ edge X-ray absorption near-edge structure (XANES) measurements were performed on the 06ID superconducting wiggler hard X-ray microanalysis (HXMA) beamline at the Canadian Light Source (CLS) with a premirror-double crystal monochromator-postmirror configuration using $\mathrm{Si}$ (111) crystals and Rh mirrors. CLS operates at $2.9 \mathrm{GeV}$ with $175 \mathrm{~mA}$ injection current and the beamline wiggler was running at $1.5 \mathrm{~T}$. Measurements were made at room temperature in transmission mode for Ta foil with ion chambers filled with $100 \%$ of $\mathrm{N}_{2}$ and in fluorescence mode for the lithium tantalate thin films using a 32-element Ge detector.

To prepare the sample for impedance testing, $\sim 50 \mathrm{~nm} \mathrm{Au}$ layer was first sputtered on the glass substrate in a Polaron sputtering system under $2 \mathrm{kV}$ for $9 \mathrm{~min}$, and then the lithium tantalate thin film was deposited on top of the Au layer using a pulsing sequence of $400 \times\left(1 \times \mathrm{Li}_{2} \mathrm{O}+6 \times \mathrm{Ta}_{2} \mathrm{O}_{5}\right)$. Following the ALD deposition, the as-prepared sample was immediately transferred into the Polaron sputtering system for coating of another Au layer ( $\sim 50 \mathrm{~nm}$ in thickness). The thickness of the lithium tantalate thin film (or the distance between the two $\mathrm{Au}$ layers) was measured to be $\sim 200 \mathrm{~nm}$, and the area of lithium tantalate thin film was $5 \mathrm{~mm} \times 5 \mathrm{~mm}$. The impedance spectra at different temperatures were obtained by applying $50 \mathrm{mV}$ in a frequency range of $200 \mathrm{kHz}-10 \mathrm{~Hz}$ on a CHI electrochemistry workstation. The sample was left to stabilize at each temperature for $30 \mathrm{~min}$ before acquiring data.

\section{RESULTS AND DISCUSSION}

Figures $1 \mathrm{a}$ and $1 \mathrm{~b}$ show the effect of $\mathrm{LiO}^{t} \mathrm{Bu}$ and $\mathrm{Ta}(\mathrm{OEt})_{5}$ pulse times on the growth per cycle (GPC) of the lithium tantalate system deposited using a pulsing sequence of $(1 \times$ $\left.\mathrm{Li}_{2} \mathrm{O}+1 \times, \mathrm{Ta}_{2} \mathrm{O}_{5}\right)$. It can be seen that the GPC stabilizes at around $2.1 \AA$ Á/cycle, when pulse times for $\mathrm{Ta}(\mathrm{OEt})_{5}$ and $\mathrm{LiO}^{t} \mathrm{Bu}$ are longer than 0.5 and $1 \mathrm{~s}$, respectively. Thus, $\mathrm{Ta}(\mathrm{OEt})_{5}$ and $\mathrm{LiO}^{t} \mathrm{Bu}$ pulse lengths of 0.5 and $1 \mathrm{~s}$, respectively, are sufficient to achieve saturated growth of the lithium tantalate thin film, and are chosen to be employed in subsequent experiments.

The lithium tantalate thin films are deposited using pulsing sequences of $1 \times \mathrm{Li}_{2} \mathrm{O}+n \times \mathrm{Ta}_{2} \mathrm{O}_{5}(n=1,6$, and 10), where subcycle number of $\mathrm{Ta}_{2} \mathrm{O}_{5}(n)$ is varied in order to change film composition ( $\mathrm{Li} / \mathrm{Ta}$ ratio). The morphologies of the as-
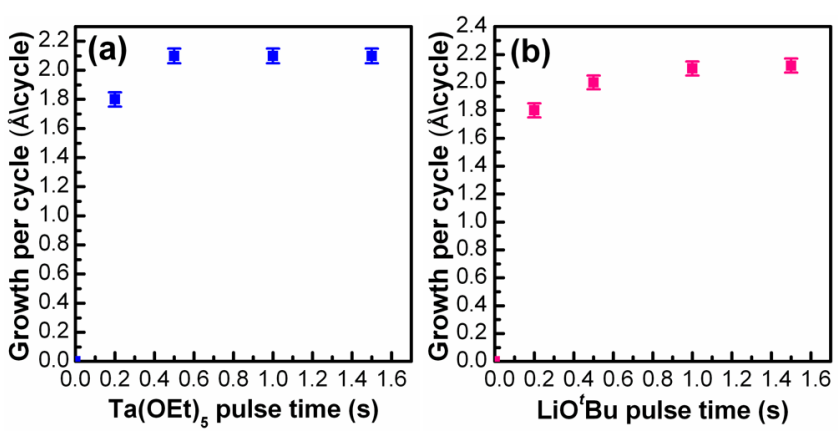

Figure 1. Growth per cycle of the lithium tantalate thin film as a function of $(\mathrm{a}) \mathrm{Ta}(\mathrm{OEt})_{5}$ pulse time and $(\mathrm{b}) \mathrm{LiO}^{t} \mathrm{Bu}$ pulse time using a pulsing sequence of $400 \times\left(1 \times \mathrm{Li}_{2} \mathrm{O}+1 \times \mathrm{Ta}_{2} \mathrm{O}_{5}\right)$.

deposited thin films are examined by SEM. Figure 2 displays the result of the lithium tantalate thin film deposited using a

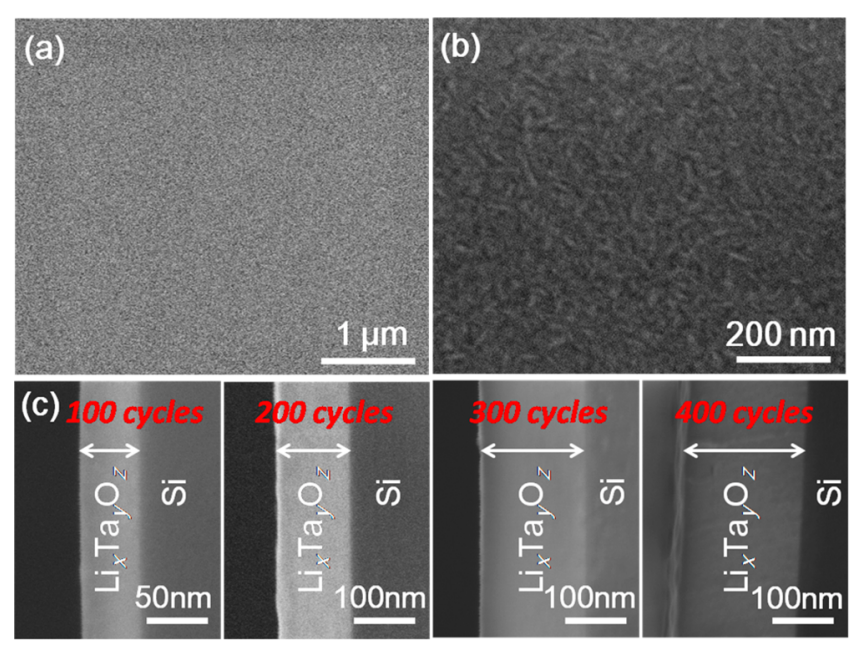

Figure 2. SEM morphology of lithium tantalate thin film deposited using a pulsing sequence of $\left(1 \times \mathrm{Li}_{2} \mathrm{O}+6 \times \mathrm{Ta}_{2} \mathrm{O}_{5}\right):(\mathrm{a}, \mathrm{b})$ top view of 400 -cycle thin film and (c) cross-section views of the thin films deposited with different ALD cycles.

pulsing sequence of $1 \times \mathrm{Li}_{2} \mathrm{O}+6 \times \mathrm{Ta}_{2} \mathrm{O}_{5}$ as an example. From top-view observation in Figure 2a, it can be seen that 400 -cycle lithium tantalate thin film is uniformly coated on the whole $\mathrm{Si}$ substrate, with a slight roughness associated with the film surface (Figure 2b). Cross-sectional views in Figure $2 \mathrm{c}$ clearly show the thicknesses of the lithium tantalate thin films deposited with different ALD cycles (low-magnification images included in Figure SI-1 of the Supporting Information). The thickness measurements by SEM are plotted as a function of ALD cycle number in Figure 3. XRD analysis (Figure SI-2) reveals amorphous structure of the as-grown lithium tantalate thin films.

Figure 3a shows the ALD-cycle dependence of lithium tantalate film thickness when different pulsing sequences are employed. It is clear that the lithium tantalate film thickness is linearly dependent with ALD cycle, demonstrating the selflimiting behavior during the ALD process. By fitting the data in Figure 3a linearly, the GPC of the lithium tantalate thin film is calculated to be $2.2,5.2$, and $7.3 \AA$ / cycle, where $n$ equals to 1,6 , and 10 , respectively, in one $\left(1 \times \mathrm{Li}_{2} \mathrm{O}+n \times \mathrm{Ta}_{2} \mathrm{O}_{5}\right)$ cycle (as plotted in Figure $3 b$ ). From Figure $3 b$, one can see that the GPC of the lithium tantalate thin films increases monotonously 

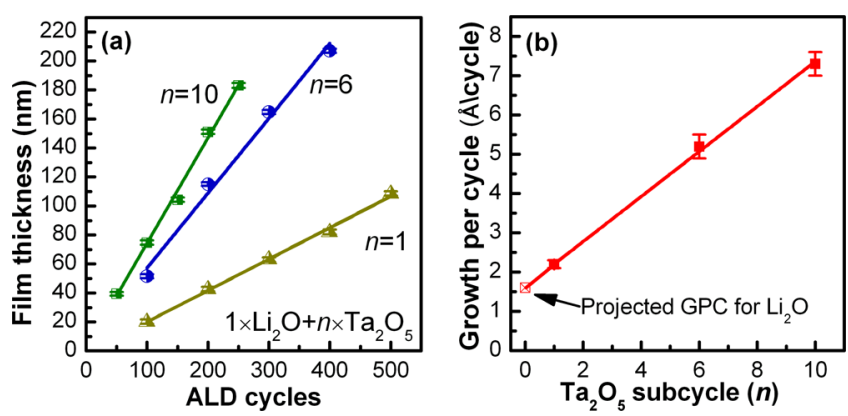

Figure 3. (a) Thickness of the lithium tantalate thin films as a function of ALD cycle number and (b) the growth per cycle of the lithium tantalate thin films as a function of $\mathrm{Ta}_{2} \mathrm{O}_{5}$ subcycle number, using pulsing sequences of $1 \times \mathrm{Li}_{2} \mathrm{O}+n \times \mathrm{Ta}_{2} \mathrm{O}_{5}(n=1,6$, and 10).

with $\mathrm{Ta}_{2} \mathrm{O}_{5}$ subcycle number $(n)$ in one complete ALD cycle $(1$ $\left.\times \mathrm{Li}_{2} \mathrm{O}+n \times \mathrm{Ta}_{2} \mathrm{O}_{5}\right)$. This trend indicates that the GPC of the lithium tantalate thin films is a linear combination of the GPC of the $\mathrm{Li}_{2} \mathrm{O}$ subcycle and $\mathrm{Ta}_{2} \mathrm{O}_{5}$ subcycle. Thereby, two parameters could be extracted from the best-linear-fit in Figure $3 \mathrm{~b}$ : the slope represents the GPC of the $\mathrm{Ta}_{2} \mathrm{O}_{5}$ subcycle $(\sim 0.5$ $\AA$ /cycle), while the $y$-axis intercept of the linear fit represents the GPC of solely the $\mathrm{Li}_{2} \mathrm{O}$ subcycle $(\sim 1.7 \AA$ Á/cycle). The GPC of the $\mathrm{Li}_{2} \mathrm{O}$ and $\mathrm{Ta}_{2} \mathrm{O}_{5}$ subcycles obtained herein have good agreement with reported valves of $\mathrm{Li}_{2} \mathrm{O}$ at $1.7 \AA /$ cycle $^{37}$ and $\mathrm{Ta}_{2} \mathrm{O}_{5}$ at $0.4 \AA /$ cycle. ${ }^{44} \mathrm{~A}$ better understanding of the ALD process can be derived from looking at the reaction mechanism for each subcycle. As proposed by Aaltonen et al., ${ }^{37}$ during the $\mathrm{Li}_{2} \mathrm{O}$ subcycle, the $\mathrm{LiO}^{t} \mathrm{Bu}$ pulse leads to the formation of two layers, resulting in a high GPC of the $\mathrm{Li}_{2} \mathrm{O}$ subcycle:

$$
\begin{aligned}
& -\mathrm{OH}^{*}+\mathrm{LiOC}\left(\mathrm{CH}_{3}\right)_{3} \rightarrow-\mathrm{O}-\mathrm{Li}^{*}+\mathrm{HOC}\left(\mathrm{CH}_{3}\right)_{3} \\
& -\mathrm{O}-\mathrm{Li}^{*}+\mathrm{LiOC}\left(\mathrm{CH}_{3}\right)_{3} \rightarrow-\mathrm{O}(-\mathrm{Li})-\mathrm{LiOC}\left(\mathrm{CH}_{3}\right)_{3}{ }^{*}
\end{aligned}
$$

where an asterisk denotes surface species. During the water pulse, the surface species generated in eq 2 are converted to hydroxide groups: ${ }^{37,45}$

$$
\begin{aligned}
& -\mathrm{O}(-\mathrm{Li})-\mathrm{LiOC}\left(\mathrm{CH}_{3}\right)_{3} *+\mathrm{H}_{2} \mathrm{O} \rightarrow-\mathrm{O}(-\mathrm{Li})-\mathrm{LiOH}^{*} \\
& +\mathrm{HOC}\left(\mathrm{CH}_{3}\right)_{3}
\end{aligned}
$$

During the $\mathrm{Ta}_{2} \mathrm{O}_{5}$ subcycle, the following surface reaction occurs: ${ }^{46}$

$$
\begin{aligned}
& n(-\mathrm{OH})^{*}+\mathrm{Ta}\left(\mathrm{OC}_{2} \mathrm{H}_{5}\right)_{5} \rightarrow \\
& \quad(-\mathrm{O}-)_{n} \mathrm{Ta}\left(\mathrm{OC}_{2} \mathrm{H}_{5}\right)_{5-n}{ }^{*}+n \mathrm{HOC}_{2} \mathrm{H}_{5} \\
& (-\mathrm{O}-)_{n} \mathrm{Ta}\left(\mathrm{OC}_{2} \mathrm{H}_{5}\right)_{5-n} *+(5-n) \mathrm{H}_{2} \mathrm{O} \\
& \rightarrow(-\mathrm{O}-)_{n} \mathrm{Ta}(\mathrm{OH})_{5-n} *+(5-n) \mathrm{HOC}_{2} \mathrm{H}_{5}
\end{aligned}
$$

Therefore, the surface reactions during one complete $(1 \times$ $\left.\mathrm{Li}_{2} \mathrm{O}+n \times \mathrm{Ta}_{2} \mathrm{O}_{5}\right)$ cycle would occur in the following sequence:

$$
\text { Equations }(1)(2) \rightarrow(3) \rightarrow(4) \stackrel{\sqrt{n}}{\rightarrow} \text { (5) }
$$

One can find that the film surfaces after $\mathrm{Li}_{2} \mathrm{O}$ and $\mathrm{Ta}_{2} \mathrm{O}_{5}$ subcycles are terminated with the same functional groups $(-\mathrm{OH})$. Thus, the surface species available after each $\mathrm{Li}_{2} \mathrm{O}$ subcycle are readily reactive sites for the succeeding $\mathrm{Ta}_{2} \mathrm{O}_{5}$ subcycle, and vice versa. This condition ensures that the $\mathrm{Li}_{2} \mathrm{O}$ and $\mathrm{Ta}_{2} \mathrm{O}_{5}$ subcycles in the combined ALD process proceed in the same manner as in each binary oxide, therefore leading to the similar GPC of $\mathrm{Li}_{2} \mathrm{O}$ and $\mathrm{Ta}_{2} \mathrm{O}_{5}$ in the ternary system as in each binary system. The self-limiting characteristic of the $\mathrm{Li}_{2} \mathrm{O}$ and $\mathrm{Ta}_{2} \mathrm{O}_{5}$ subcycles takes responsibility for the linear relationship between the lithium tantalate film thickness and ALD cycles (Figure 3a) and between the GPC of the lithium tantalate films on $\mathrm{Ta}_{2} \mathrm{O}_{5}$ subcycle number (Figure $3 \mathrm{~b}$ ). It is worth mentioning that in a ternary or quaternary system deposited by ALD, the GPC of the combined oxide processes is usually lower than what is expected from a linear combination of the GPC of each binary oxide. ${ }^{36,47}$ For example, the average GPC of $\mathrm{La}-\mathrm{Ti}-\mathrm{O}$ films grown by combining $\mathrm{La}_{2} \mathrm{O}_{3}$ and $\mathrm{TiO}_{2}$ subcycles was found to be below the theoretical GPC calculated from individual growth rate of $\mathrm{La}_{2} \mathrm{O}_{3}(0.28 \AA$ Á/cycle $)$ and $\mathrm{TiO}_{2}$ (0.52 $\mathrm{A} /$ cycle $).{ }^{36}$ The reason was most likely due to the difference in the surface chemistry between the preceding and the succeeding subcycles, which could alter the GPC of one or each binary system when they are combined. This difference was more obvious in the $\mathrm{Li}-\mathrm{La}-\mathrm{Ti}-\mathrm{O}$ system, which was fabricated using $\mathrm{Li}_{2} \mathrm{O}, \mathrm{La}_{2} \mathrm{O}_{3}$, and $\mathrm{TiO}_{2}$ subcycles. It was found that the pulsing order of the three subcycles had a substantial influence on the $\mathrm{Li}-\mathrm{La}-\mathrm{Ti}-\mathrm{O}$ films. The film grown by using a sequence of $\mathrm{TiO}_{2}-\mathrm{La}_{2} \mathrm{O}_{3}-\mathrm{Li}_{2} \mathrm{O}$ was less rough and more uniform than that deposited using a $\mathrm{TiO}_{2}-\mathrm{Li}_{2} \mathrm{O}-\mathrm{La}_{2} \mathrm{O}_{3}$ pulsing sequence. ${ }^{36}$ Thus, precursor combination and pulsing sequence should be carefully selected when depositing thin films composed of two or more ALD subcycles. From the calculation in Figure $3 b$, one can find that the GPC of the $\mathrm{Ta}_{2} \mathrm{O}_{5}$ subcycle $(\sim 0.5 \AA /$ cycle $)$ is slightly higher than that of binary $\mathrm{Ta}_{2} \mathrm{O}_{5}(0.4$ $\AA$ /cycle) reported in the literature. ${ }^{44}$ The higher GPC of $\mathrm{Ta}_{2} \mathrm{O}_{5}$ in our case might be due to denser regeneration of hydroxide groups after each $\mathrm{Li}_{2} \mathrm{O}$ subcycle (eq 3 ) than those produced after each $\mathrm{Ta}_{2} \mathrm{O}_{5}$ subcycle (eq 5). Another reason that cannot be excluded is the possibility of physisorbed water remaining on the surface after reaction 3 and/or reaction 5. Physisorbed water may lead to CVD-like growth of thin film during the $\mathrm{Ta}(\mathrm{OEt})_{5}$ pulse, thus leading to a higher GPC of $\mathrm{Ta}_{2} \mathrm{O}_{5}$ than expected.

The structure of amorphous materials is difficult to determine by diffraction-based techniques due to the lack of long-range order. By contrast, X-ray spectroscopy is sensitive to the local environment of the element to be examined and thus is ideal and powerful for analyzing amorphous materials. ${ }^{48}$ By comparing the X-ray spectra of unknown and reference materials, it is possible to gain insight into the structure of noncrystalline materials. ${ }^{48,49}$ Thus, XANES and XPS techniques were employed to study the structure or/and composition of the amorphous lithium tantalate thin films deposited by ALD in this work. Figure 4 displays XANES at $\mathrm{Ta}_{3}$ edge for the lithium tantalate thin films, in comparison with reference crystalline $\mathrm{LiTaO}_{3}$ and pure Ta. The peak at the $\mathrm{L}_{3}$ edge arises from $\mathrm{Ta} 2 \mathrm{p}_{3 / 2}$ to unoccupied $\mathrm{Ta} 5 \mathrm{~d}$ states via dipole transition, and its intensity is expected to be higher in $\mathrm{LiTaO}_{3}$ and exhibits a blue shift since $\mathrm{Ta}$ is in a higher oxidation state ( $\mathrm{d}$ charge depletion). In Figure 4, it can be seen that all the lithium tantalate thin films have very similar $\mathrm{Ta} \mathrm{L}_{3}$-edge spectrum to reference $\mathrm{LiTaO}_{3}$, except that the lithium tantalate thin films exhibit one broad peak at $\sim 9886.5 \mathrm{eV}$, instead of two wellresolved peaks at 9884.5 and $9886.8 \mathrm{eV}$ for reference crystalline $\mathrm{LiTaO}_{3}{ }^{50}$ This slight difference is attributable to the amorphous state of the lithium tantalate thin films. ${ }^{51,52}$ In Figure 4, it is also obvious that the $\mathrm{Ta}_{3}$-edge XANES of the lithium tantalate thin films are remarkably different from that of 


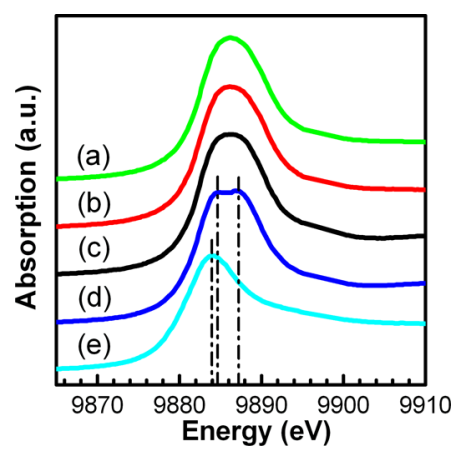

Figure 4. $\mathrm{Ta}_{3}$-edge XANES spectra of lithium tantalate thin films deposited using pulsing sequences of $1 \times \mathrm{Li}_{2} \mathrm{O}+n \times \mathrm{Ta}_{2} \mathrm{O}_{5}$ where (a) $n=1$, (b) $n=6$, and (c) $n=10$, (d) reference crystalline $\mathrm{LiTaO}_{3}$, and (e) pure Ta.

pure Ta metal as expected. The XANES result indicates that the $\mathrm{Ta}$ in lithium tantalate thin films have similar chemical binding $(\mathrm{Li}-\mathrm{O}-\mathrm{Ta})$ as that in reference $\mathrm{LiTaO}_{3}$ with a noticeable broadening due to disorder.

Compositions of the lithium tantalate thin films were analyzed by XPS, and the results are displayed in Figure 5. The XPS survey in Figure 5a indicates the presence of $\mathrm{Li}, \mathrm{Ta}$, and $\mathrm{O}$ elements in all the lithium tantalate thin films (their atomic percentages listed in SI-Table 1). The chemical formula is determined as $\mathrm{Li}_{12.3} \mathrm{TaO}_{z}, \mathrm{Li}_{5.1} \mathrm{TaO}_{z}$, and $\mathrm{Li}_{0.6} \mathrm{TaO}_{z}$, for the lithium tantalate thin film deposited using a $\mathrm{Ta}_{2} \mathrm{O}_{5}$ subcycle number of 1,6 , and 10 , respectively, while $\mathrm{Li}_{2} \mathrm{O}$ was kept constant at 1 . XPS data reveal that the $\mathrm{Li} / \mathrm{Ta}$ ratio of the lithium tantalate thin films decreases with increasing $\mathrm{Ta}_{2} \mathrm{O}_{5}$ subcycle number, as plotted in Figure $5 \mathrm{~b}$. Figure $5 \mathrm{c}$ illustrates the chemical environment of Ta element in the lithium tantalate thin films by analyzing the $\mathrm{Ta} 4 \mathrm{f}$ spectrum. For $\mathrm{Li}_{12.3} \mathrm{TaO}_{z}$ and $\mathrm{Li}_{5.1} \mathrm{TaO}_{z}$, the $\mathrm{Ta}$ 4f spectrum is fitted into one set of doublet $\mathrm{Ta} 4 \mathrm{f}_{5 / 2}$ (peak A) and $\mathrm{Ta} 4 \mathrm{f}_{7 / 2}$ (peak B). The positions of $\mathrm{Ta}_{4} 4 \mathrm{f}_{5 / 2}$ (peak A) and $\mathrm{Ta} 4 \mathrm{f}_{7 / 2}$ (peak B) are centered at 27.7 and $25.8 \mathrm{eV}$ for $\mathrm{Li}_{12.3} \mathrm{TaO}_{z}$ and at 27.9 and 26.0 $\mathrm{eV}$ for $\mathrm{Li}_{5.1} \mathrm{TaO}_{z}$, respectively. The slight shift of $\mathrm{Ta} 4 \mathrm{f}_{5 / 2}$ (peak A) and $\mathrm{Ta} 4 \mathrm{f}_{7 / 2}$ (peak $\mathrm{B}$ ) is due to the stoichiometry change from $\mathrm{Li}_{12.3} \mathrm{TaO}_{z}$ to $\mathrm{Li}_{5.1} \mathrm{TaO}_{z}$. The positions of the $\mathrm{Ta} 4 \mathrm{f}_{5 / 2}$ (peak A) and Ta $4 \mathrm{f}_{7 / 2}$ (peak B) are very close to those reported in stoichiometric $\mathrm{LiTaO}_{3}$ film, ${ }^{53}$ revealing that the $\mathrm{Ta}$ in $\mathrm{Li}_{12.3} \mathrm{TaO}_{z}$ and $\mathrm{Li}_{5.1} \mathrm{TaO}_{z}$ has a similar chemical binding $(\mathrm{Li}-$ $\mathrm{O}-\mathrm{Ta}$ ) as stoichiometric $\mathrm{LiTaO}_{3}$. Deconvolution of $\mathrm{Ta} 4 \mathrm{f}$ peak of $\mathrm{Li}_{0.6} \mathrm{TaO}_{z}$ is composed of two pairs of doublets. The one pair of $\mathrm{Ta} 4 \mathrm{f}_{5 / 2}$ (peak A) and $\mathrm{Ta} 4 \mathrm{f}_{7 / 2}$ (peak B) at lower binding energy are consistent with those in $\mathrm{Li}_{5.1} \mathrm{TaO}_{z}$. The other pair of Ta $4 \mathrm{f}_{5 / 2}$ (peak $\mathrm{A}^{\prime}$ ) and $\mathrm{Ta} 4 \mathrm{f}_{7 / 2}$ (peak $\mathrm{B}^{\prime}$ ) at higher binding energy are located at 29.2 and $27.3 \mathrm{eV}$, respectively, which seem similar to the binding energy of $\mathrm{Ta}$ in stoichiometric $\mathrm{Ta}_{2} \mathrm{O}_{5} .{ }^{54}$ This result indicates that the Ta element in $\mathrm{Li}_{0.6} \mathrm{TaO}_{z}$ exists in two types of chemical environments, i.e., $\mathrm{Li}-\mathrm{O}-\mathrm{Ta}$ and $\mathrm{Ta}-$ $\mathrm{O}-\mathrm{Ta}$, which make up $82 \%$ and $18 \%$, respectively. The appearance of $\mathrm{Ta}-\mathrm{O}-\mathrm{Ta}$ obviously resulted from the more $\mathrm{Ta}_{2} \mathrm{O}_{5}$ subcycles employed during the deposition of $\mathrm{Li}_{0.6} \mathrm{TaO}_{z}$. Besides the above elements, carbon is also detected in all thin films prepared (Figure 5a). The presence of carbon can be addressed to organic carbons in $\mathrm{C}-\mathrm{C}, \mathrm{C}-\mathrm{H}(284.8 \mathrm{eV}), \mathrm{C}-$ $\mathrm{OH}, \mathrm{C}-\mathrm{O}-\mathrm{C}(286.3 \mathrm{eV}), \mathrm{O}-\mathrm{C}=\mathrm{O}(288.8 \mathrm{eV})$, and $\mathrm{C}=\mathrm{O}$ $(287.2 \mathrm{eV})$ (see Figure SI-3). The source of carbon is a result of ligand residue of ALD precursors as well as hydrocarbons present in ambient air. ${ }^{55}$ In $\mathrm{Li}_{12.3} \mathrm{TaO}_{z}$, another major source of carbon impurity is carbonate $(290.1 \mathrm{eV})$ (Figure SI-3), which is commonly found in lithium-containing thin films produced by ALD. ${ }^{37,55}$ Carbonate present results from a reaction between $\mathrm{Li}_{2} \mathrm{O}$ and ambient carbon dioxide when the thin films are exposed to air ${ }^{45}$ and thereby should predominantly reside on the topmost surface of the thin film. ${ }^{37,55}$ In $\mathrm{Li}_{5.1} \mathrm{TaO}_{z}$ and $\mathrm{Li}_{0.6} \mathrm{TaO}_{z}$, carbonate only accounts for $4-6 \%$ of the carbon impurity compared to $40 \%$ in $\mathrm{Li}_{12.3} \mathrm{TaO}_{z}$ (Figure SI-3). This difference could be explained by the fact that more $\mathrm{Ta}_{2} \mathrm{O}_{5}$ subcycles were used in ALD process of $\mathrm{Li}_{5.1} \mathrm{TaO}_{z}$ and $\mathrm{Li}_{0.6} \mathrm{TaO}_{z}$ than $\mathrm{Li}_{12.3} \mathrm{TaO}_{z}$, and resultant thicker $\mathrm{Ta}_{2} \mathrm{O}_{5}$ layer in the former films can better prevent the reaction of $\mathrm{Li}_{2} \mathrm{O}$ with ambient carbon dioxide. $\mathrm{Li}_{5.1} \mathrm{TaO}_{z}$ thin film is chosen to be further studied in terms of the lithium-ion conductivity because it is stable in air and easy for operation. More importantly, the excess $\mathrm{Li}$ content in $\mathrm{Li}_{5.1} \mathrm{TaO}_{z}$ thin film is beneficial for lithiumion conduction according to previous studies. ${ }^{53,56}$

Lithium-ion conductivity of 400 -cycle $\mathrm{Li}_{5.1} \mathrm{TaO}_{z}$ thin film ( $\sim 200 \mathrm{~nm}$ thick) was assessed by using electrochemical impedance spectroscopy. Figure 6a shows Cole-Cole plots of the $\mathrm{Li}_{5.1} \mathrm{TaO}_{z}$ thin film measured at different temperatures. It can be seen that each Cole-Cole plot consists of one semicircle in the high-frequency region and an inclined tail in the lowfrequency region. The former semicircle could be assigned to the bulk resistance of $\mathrm{Li}_{5.1} \mathrm{TaO}_{z}$ solid-state electrolyte, ${ }^{42}$ while the latter is attributable to the polarization at electrodeelectrolyte interface. ${ }^{57}$ It is worth noting that the inclined tail in
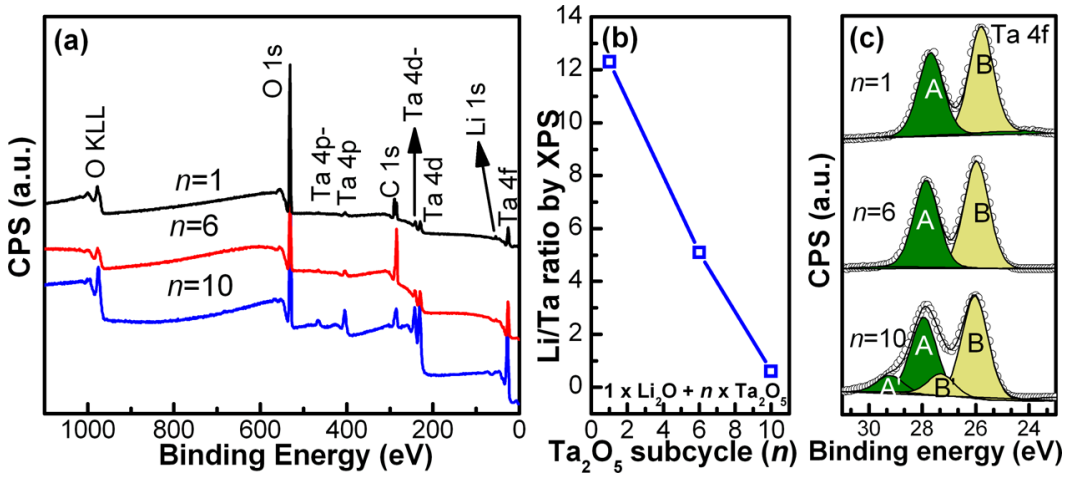

Figure 5. (a) XPS survey of the lithium tantalate thin films deposited using pulsing sequences of $1 \times \mathrm{Li}_{2} \mathrm{O}+n \times \mathrm{Ta}_{2} \mathrm{O}_{5}(n=1,6$, and 10$)$, (b) $\mathrm{Li} / \mathrm{Ta}$ ratio in the thin films as a function of $\mathrm{Ta}_{2} \mathrm{O}_{5}$ subcycle number $(n)$, and (c) deconvolution of $\mathrm{Ta} 4 \mathrm{f}$ spectra. In $(\mathrm{c})$, the components $\mathrm{A}$ and $\mathrm{A}^{\prime}$ correspond to the $\mathrm{Ta}_{\mathrm{f}} 4 \mathrm{f}_{5 / 2}$ lines, and the components $\mathrm{B}$ and $\mathrm{B}^{\prime}$ correspond to the $\mathrm{Ta} 4 \mathrm{f}_{7 / 2}$ lines. 

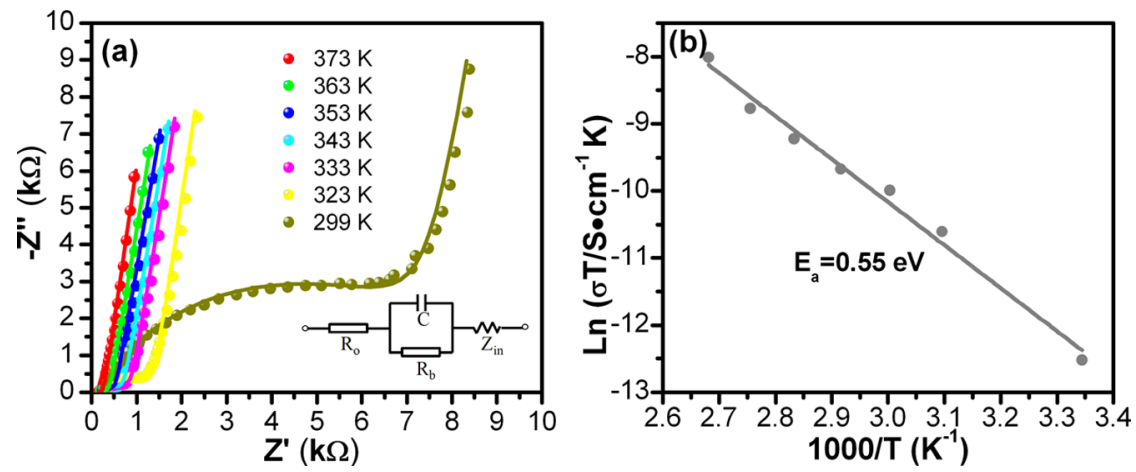

Figure 6. (a) Impedance plots of the $\mathrm{Li}_{5.1} \mathrm{TaO}_{z}$ thin film measured at different temperatures (inset shows the equivalent circuit for fitting). (b) Arrhenius plot of the ionic conductivity of the $\mathrm{Li}_{5.1} \mathrm{TaO}_{z}$ thin film.

Table 1. Comparisons of Lithium Tantalate and $\mathrm{Li}_{2} \mathrm{O}-\mathrm{Al}_{2} \mathrm{O}_{3}$ Solid-State Electrolytes

\begin{tabular}{|c|c|c|c|c|c|}
\hline solid-state electrolyte & substrate type & $\begin{array}{c}\mathrm{Li}^{+} \text {conductivity } \\
(\mathrm{S} / \mathrm{cm})\end{array}$ & $\begin{array}{c}\text { activation energy } \\
(\mathrm{eV})\end{array}$ & $\begin{array}{l}\text { preparation } \\
\text { method }\end{array}$ & ref \\
\hline amorphous $\mathrm{Li}_{x} \mathrm{TaO}_{y}$ & ITO film (planar) & $8 \times 10^{-8}($ at $300 \mathrm{~K})$ & 0.25 & RF sputtering & 42 \\
\hline $\mathrm{Li}_{2} \mathrm{O}-\mathrm{Al}_{2} \mathrm{O}_{3}$ & sapphire/Si(111) (planar) & $1 \times 10^{-7}($ at $573 \mathrm{~K})$ & 2.90 & ALD & 37 \\
\hline amorphous $\mathrm{Li}_{5.1} \mathrm{TaO}_{z}$ & $\mathrm{Si}(100) /$ glass (planar); $\mathrm{AAO}(3 \mathrm{D}$, aspect ratio $\sim 300)$ & $2 \times 10^{-8}($ at $299 \mathrm{~K})$ & 0.55 & ALD & this work \\
\hline
\end{tabular}

the case of ionic blocking electrodes (such as Au used herein) is typical indication that the investigated solid-state electrolyte is predominately ionic conductor in nature. ${ }^{57,58}$ The Cole-Cole plots could be well-resolved using the equivalent circuit inset in Figure 6a, in which $R_{\mathrm{b}}$ and $C$ represent the bulk resistance and the resultant capacitance of the $\mathrm{Li}_{5.1} \mathrm{TaO}_{z}$ solid-state electrolyte, respectively, $Z_{\text {in }}$ denotes the polarization impedance of the electrode-electrolyte interface, and $R_{\mathrm{o}}$ is the ohmic resistance of the electrodes. ${ }^{42} R_{\mathrm{b}}$ values are obtained in Figure $6 \mathrm{a}$ at different temperatures, and the ionic conductivity of the $\mathrm{Li}_{5.1} \mathrm{TaO}_{z}$ solid-state electrolyte is derived from the equation ${ }^{59}$

$$
\sigma=d / A R_{\mathrm{b}}
$$

where $\sigma$ is the ionic conductivity, $d$ is the thickness of the $\mathrm{Li}_{5.1} \mathrm{TaO}_{z}$ film, and $A$ is the area of the $\mathrm{Li}_{5.1} \mathrm{TaO}_{z}$ film between $\mathrm{Au}$ electrodes. The ionic conductivity of $\mathrm{Li}_{5.1} \mathrm{TaO}_{z}$ varies from $1.2 \times 10^{-8}$ to $9.0 \times 10^{-7} \mathrm{~S} / \mathrm{cm}$, at temperatures between 299 and $373 \mathrm{~K}$. Furthermore, variation of the ionic conductivity with temperature is shown in an Arrhenius representation according to ${ }^{59,60}$

$$
\sigma T=\sigma_{0} \exp \left[-E_{\mathrm{a}} /(k T)\right]
$$

where $E_{\mathrm{a}}$ denotes the activation energy, $k$ is the Boltzmann constant, $T$ is the absolute temperature, and $\sigma_{0}$ is a constant. Activation energy of $\sim 0.55 \mathrm{eV}$ is obtained by fitting the temperature dependence of the lithium-ion conductivity in Figure 6b. Comparisons are made between $\mathrm{Li}_{5.1} \mathrm{TaO}_{z}, \mathrm{Li}_{x} \mathrm{TaO}_{y}$ prepared by $\mathrm{RF}$ sputtering and $\mathrm{Li}_{2} \mathrm{O}-\mathrm{Al}_{2} \mathrm{O}_{3}$ grown by ALD in Table 1. It can be found that the lithium-ion conductivity of $\mathrm{Li}_{5.1} \mathrm{TaO}_{z}\left(2 \times 10^{-8} \mathrm{~S} / \mathrm{cm}\right.$ at $\left.299 \mathrm{~K}\right)$ is comparable with that of amorphous $\mathrm{Li}_{x} \mathrm{TaO}_{y}$ prepared by $\mathrm{RF}$ sputtering $\left(8 \times 10^{-8} \mathrm{~S} / \mathrm{cm}\right.$ at $300 \mathrm{~K}) .{ }^{42}$ For the $\mathrm{Li}_{2} \mathrm{O}-\mathrm{Al}_{2} \mathrm{O}_{3}$, its lithium-ion conductivity was estimated to be around $1 \times 10^{-7} \mathrm{~S} / \mathrm{cm}$ at $573 \mathrm{~K}$, and no data at room temperature was reported. ${ }^{37}$ Furthermore, the $\mathrm{Li}_{2} \mathrm{O}-\mathrm{Al}_{2} \mathrm{O}_{3}$ exhibits a much higher activation energy $(2.9 \mathrm{eV})$ than $\mathrm{Li}_{5.1} \mathrm{TaO}_{z}(0.55 \mathrm{eV})$ and amorphous $\mathrm{Li}_{x} \mathrm{TaO}_{y}(0.25 \mathrm{eV})$. The lithium-ion conductivity of $\mathrm{Li}_{5.1} \mathrm{TaO}_{z}$ is considerably low compared with popular solid-state electrolytes (such as NASICON-type, Garnet-type $)^{61,62}$ deposited by the PVD method in $2 \mathrm{D}$ batteries. However, these popular solid-state electrolytes are not applicable in 3D microbatteries due to the limitation of their preparation method (PVD) in 3D substrates. For applications in 3D microbatteries, the deposition technique should allow uniform coating of solid-state electrolytes in a 3D architecture. $\mathrm{Li}_{5.1} \mathrm{TaO}_{z}$ prepared by ALD in our case does meet this requirement for $3 \mathrm{D}$ microbatteries, as demonstrated in Figure 7. Moreover, compared with solid-state electrolytes

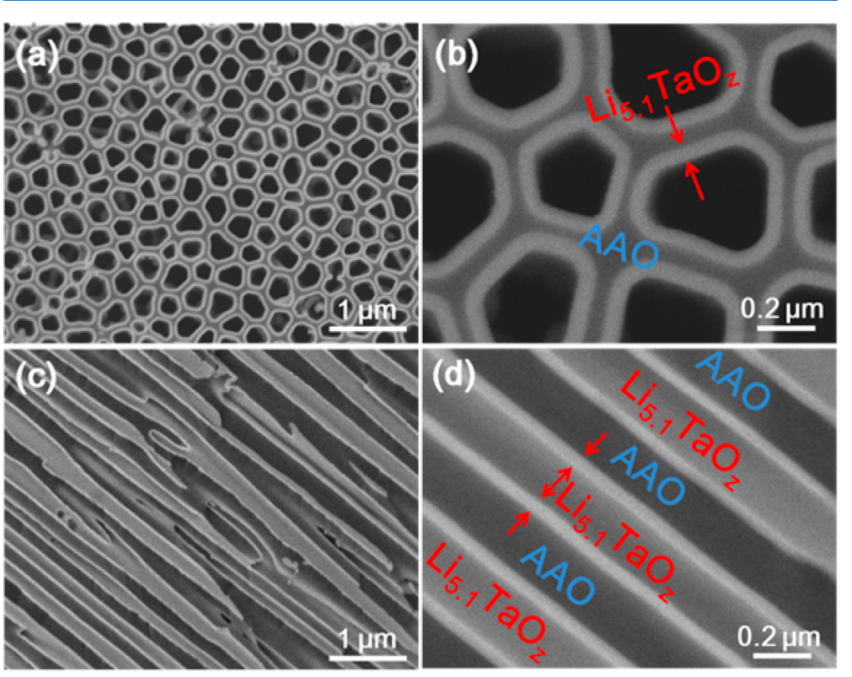

Figure 7. Backscattered electron (BSE) images of 100-cycle $\mathrm{Li}_{5.1} \mathrm{TaO}_{z}$ thin film deposited in AAO template: (a, b) top-view and (c, d) crosssection view.

prepared by PVD, ALD-deposited $\mathrm{Li}_{5.1} \mathrm{TaO}_{z}$ has much thinner film thickness, which in return can greatly reduce its internal resistance. ${ }^{59}$ Therefore, successful achievement of uniform and thin coating of solid-state electrolytes in 3D architecture will allow for significantly reduced ionic conductivity to be a tolerable consequence. ${ }^{42}$

The capability of the ALD process to achieve the above goal is demonstrated by depositing 100 -cycle $\mathrm{Li}_{5.1} \mathrm{TaO}_{z}$ thin film on an AAO template with aspect ratio of $\sim 300$, as shown in Figure 7. Top-view images in Figure $7 \mathrm{a}, \mathrm{b}$ indicate that the $\mathrm{Li}_{5.1} \mathrm{TaO}_{z}$ 
thin film is uniformly and conformally coated around the pores of the AAO template. Furthermore, cross-section examination, as seen in Figure $7 c, d$, shows that the inner surface of the pores is covered by a tubular thin film of $\mathrm{Li}_{5.1} \mathrm{TaO}_{z}$. The thickness of the $\mathrm{Li}_{5.1} \mathrm{TaO}_{z}$ thin film is measured as $\sim 50 \mathrm{~nm}$ from the top (Figure $7 \mathrm{~b}$ ) and the side (Figure $7 \mathrm{~d}$ ). The BSE images in Figure 7 clearly illustrate that the ALD process developed herein is capable of depositing desirable lithium tantalate thin films in high-aspect-ratio substrates, as required in $3 \mathrm{D}$ microbatteries.

\section{CONCLUSION}

Lithium tantalate thin films have been deposited by means of ALD through combining subcycles of $\mathrm{Li}_{2} \mathrm{O}\left(\mathrm{LiO}^{t} \mathrm{Bu}-\mathrm{H}_{2} \mathrm{O}\right)$ and $\mathrm{Ta}_{2} \mathrm{O}_{5}\left(\mathrm{Ta}(\mathrm{OEt})_{5}-\mathrm{H}_{2} \mathrm{O}\right)$. All lithium tantalate thin films were deposited at $225^{\circ} \mathrm{C}$, and they were amorphous at as-deposited state. The growth of the lithium tantalate thin films by ALD was proven to be a self-limiting process. Composition ( $\mathrm{Li} / \mathrm{Ta}$ ratio) of the lithium tantalate thin films was controlled by changing the subcycle ratios of $\mathrm{Li}_{2} \mathrm{O}$ to $\mathrm{Ta}_{2} \mathrm{O}_{5}$ ( 1 to 1,1 to 6 , and 1 to 10). Both XPS and XANES analysis confirmed that Ta in the lithium tantalate thin films had similar chemical environment as that in reference $\mathrm{LiTaO}_{3}$. The as-grown lithium tantalate thin film using $1 \mathrm{Li}_{2} \mathrm{O}$ and $6 \mathrm{Ta}_{2} \mathrm{O}_{5}$ subcycles exhibited a lithium-ion conductivity of $2 \times 10^{-8} \mathrm{~S} / \mathrm{cm}$ at room temperature. Moreover, the ALD process developed in this work successfully deposited lithium tantalate thin films with excellent uniformity and conformality in a 3D AAO template with an aspect ratio of $\sim 300$. Given the aforementioned unique advantages, the lithium tantalate thin films prepared by ALD might find potential applications as solid-state electrolytes in 3D lithium-ion microbatteries, which is very promising power supply system for next-generation microelectronic devices.

\section{ASSOCIATED CONTENT}

\section{S Supporting Information}

Low-magnification SEM images of the lithium tantalate thin film deposited using pulsing sequence of $1 \times \mathrm{Li}_{2} \mathrm{O}+6 \times \mathrm{Ta}_{2} \mathrm{O}_{5}$ with different ALD cycles; XRD pattern of 400-cycle lithium tantalate thin film deposited using pulsing sequence of $1 \times$ $\mathrm{Li}_{2} \mathrm{O}+6 \times \mathrm{Ta}_{2} \mathrm{O}_{5}$ on the glass substrate; deconvolution of $\mathrm{C}$ $1 \mathrm{~s} / 4$ spectrum of the lithium tantalate thin films deposited using different pulsing sequences; elemental compositions of lithium tantalate thin films deposited using different pulsing sequences as measured by XPS. This material is available free of charge via the Internet at http://pubs.acs.org.

\section{AUTHOR INFORMATION}

\section{Corresponding Author}

*Tel + 15196612111 x87759; fax + 1519661 3020; e-mail xsun@eng.uwo.ca (X.S.).

\section{Notes}

The authors declare no competing financial interest.

\section{ACKNOWLEDGMENTS}

This work was supported by General Motors of Canada, Natural Sciences and Engineering Research Council of Canada (NSERC), Canada Fundation for Innovation (CFI), Ontario Research Fund (ORF), Canadian Light Source (CLS) at University of Saskatchewan, and University of Western Ontario.

\section{REFERENCES}

(1) Long, J. W.; Dunn, B.; Rolison, D. R.; White, H. S. ThreeDimensional Battery Architectures. Chem. Rev. 2004, 104, 4463-2292.

(2) Roberts, M.; Johns, P.; Owen, J.; Brandell, D.; Edstrom, K.; Enany, G. E.; Guery, C.; Golodnitsky, D.; Lacey, M.; Lecoeur, C.; et al. 3D Lithium Ion Batteries-from Fundamentals to Fabrication. J. Mater. Chem. 2011, 21, 9876-9890.

(3) Oudenhoven, J. F. M.; Baggetto, L.; Notten, P. H. L. All-SolidState Lithium-Ion Microbatteries: a Review of Various ThreeDimensional Concepts. Adv. Energy Mater. 2011, 1, 10-33.

(4) Bates, J. B.; Dudney, N. J.; Neudecker, B.; Ueda, A.; Evans, C. D. Thin-Film Lithium and Lithium-Ion Batteries. Solid State Ionics 2000, $135,33-45$.

(5) Souquet, J. L.; Duclot, M. Thin Film Lithium Batteries. Solid State Ionics 2002, 148, 375-379.

(6) Arthur, T. S.; Bates, D. J.; Cirigliano, N.; Jhonson, D. C.; Malati, P.; Mosby, J. M.; Perre, E.; Rawls, M. T.; Prieto, A. L.; Dunn, B. ThreeDimensional Electrodes and Battery Architectures. MRS Bull. 2011, 36, 523-531.

(7) Notten, P. H. L.; Roozeboom, F.; Niessen, R. A. H.; Baggetto, L. 3-D Integrated All-Solid-State Rechargeable Batteries. Adv. Mater. 2007, 19, 4564-4567.

(8) Dunn, B.; Long, J. W.; Rolison, D. R. Rethinking Multifunction in Three Dimensions for Miniaturizing Electrical Energy Storage. Electrochem. Soc. Interface 2008, 17, 49-53.

(9) Golodnitsky, D.; Nathan, M.; Yufit, V.; Strauss, E.; Freedman, K.; Burstein, L.; Gladkich, A.; Peled, E. Progress in Three-Dimensional (3D) Li-Ion Microbatteries. Solid State Ionics 2006, 177, 2811-2819.

(10) Rolison, D. R.; Long, J. W.; Lytle, J. C.; Fischer, A. E.; Rhodes, C. P.; Mcevoy, T. M.; Bourg, M. E.; Lubers, A. M. Multifunctional 3D Nanoarchitectures for Energy Storage and Conversion. Chem. Soc. Rev. 2009, 38, 226-252.

(11) Bae, C.; Shin, H.; Nielsch, K. Surface Modification and Fabrication of 3D Nanostructures by Atomic Layer Deposition. MRS Bull. 2011, 36, 887-897.

(12) George, S. M. Atomic Layer Deposition: an Overview. Chem. Rev. 2010, 110, 111-131.

(13) Puurunen, R. L. Surface Chemistry of Atomic Layer Deposition: a Case Study for the Trimethylaluminum/Water Process. J. Appl. Phys. 2005, 97, 121301.

(14) Elam, J. W.; Routkevitch, D.; Mardilovich, P. P.; George, S. M. Conformal Coating on Ultrahigh-Aspect-Ratio Nanopores of Anodic Alumina by Atomic Layer Deposition. Chem. Mater. 2003, 15, 35073517.

(15) Cheah, S. K.; Perre, E.; Rooth, M.; Fondell, M.; Hårsta, A.; Nyholm, L.; Boman, M.; Gustafsson, T.; Lu, J.; Simon, P.; et al. SelfSupported Three-Dimensional Nanoelectrodes for Microbattery Applications. Nano Lett. 2009, 9, 3230-3233.

(16) Gerasopoulos, K.; Chen, X.; Culver, J.; Wang, C.; Ghodssi, R. Self-Assembled $\mathrm{Ni} / \mathrm{TiO}_{2}$ Nanocomposite Anode Synthesized via Electroless Plating and Atomic Layer Deposition on Biological Scaffolds. Chem. Commun. 2010, 46, 7349-7351.

(17) Gerasopoulos, K.; Pomerantseva, E.; McCarthy, M.; Brown, A.; Wang, C.; Culver, J.; Ghodssi, R. Hierarchical Three-Dimensional Microbattery Electrodes Combining Bottom-Up Self-Assembly and Top-Down Micromachining. ACS Nano 2012, 6, 6422-6432.

(18) Li, X.; Meng, X.; Liu, J.; Geng, D.; Zhang, Y.; Banis, M. N.; Li, Y.; Yang, J.; Li, R.; Sun, X.; et al. Tin Oxide with Controlled Morphology and Crystallinity by Atomic Layer Deposition onto Graphene Nanosheets for Enhanced Lithium Storage. Adv. Funct. Mater. 2012, 22, 1647-1654.

(19) Chen, X.; Pomerantseva, E.; Banerjee, P.; Gregorczyk, K.; Ghodssi, R.; Rubloff, G. Ozone-Based Atomic Layer Deposition of Crystalline $\mathrm{V}_{2} \mathrm{O}_{5}$ for High Performance Electrochemical Energy Storage. Chem. Mater. 2012, 24, 1255-1261.

(20) Meng, X.; Liu, J.; Li, X.; Banis, M. N.; Yang, J.; Li, R.; Sun, X. Atomic Layer Deposited $\mathrm{Li}_{4} \mathrm{Ti}_{5} \mathrm{O}_{12}$ on Nitrogen-Doped Carbon Nanotubes. RSC Adv. 2013, 3, 7285-7288. 
(21) Kim, S. W.; Han, T. H.; Kim, J.; Gwon, H.; Moon, H. S.; Kang, S. W.; Kim, S. O.; Kang, K. Fabrication and Electrochemical Characterization of $\mathrm{TiO}_{2}$ Three-Dimensional Nanonetwork Based on Peptide Assembly. ACS Nano 2009, 3, 1085-1090.

(22) Meng, X.; Zhong, Y.; Sun, Y.; Banis, M. N.; Li, R.; Sun, X. Nitrogen-Doped Carbon Nanotubes Coated by Atomic Layer Deposited $\mathrm{SnO}_{2}$ with Controlled Morphology and Phase. Carbon 2011, 49, 1133-1144.

(23) Scott, I. D.; Jung, Y. S.; Cavanagh, A. S.; Yan, Y.; Dillon, A. C.; George, S. M.; Lee, S.-H. Ultrathin Coatings on Nano- $\mathrm{LiCoO}_{2}$ for LiIon Vehicular Applications. Nano Lett. 2011, 11, 414-418.

(24) Guan, D.; Jeevarajan, J. A.; Wang, Y. Enhanced Cycleability of $\mathrm{LiMn}_{2} \mathrm{O}_{4}$ Cathodes by Atomic Layer Deposition of Nanosized-Thin $\mathrm{Al}_{2} \mathrm{O}_{3}$ Coatings. Nanoscale 2011, 3, 1465-1469.

(25) Zhao, J.; Qu, G.; Flake, J. C.; Wang, Y. Low Temperature Preparation of Crystalline $\mathrm{ZrO}_{2}$ Coatings for Improved ElevatedTemperature Performance of Li-Ion Battery Cathodes. Chem. Commun. 2012, 48, 8108-8110.

(26) Jung, Y. S.; Cavanagh, A. S.; Riely, L. A.; Kang, S.-H.; Dillon, A. C.; Groner, M. D.; George, S. M.; Lee, S.-H. Ultrathin Direct Atomic Layer Deposition on Composite Electrodes for Highly Durable and Safety Li-Ion Batteries. Adv. Mater. 2010, 22, 2172-2176.

(27) Zhao, J.; Wang, Y. Ultrathin Surface Coatings for Improved Electrochemical Performance of Lithium Ion Battery Electrodes at Elevated Temperature. J. Phys. Chem. C 2012, 116, 11867-11876.

(28) Ann, D.; Xiao, X. Extended Lithium Titanate Cycling Potential Window with Near Zero Capacity Loss. Electrochem. Commun. 2011, 13, 796-799.

(29) Liu, J.; Li, X.; Cai, M.; Li, R.; Sun, X. Ultrathin Atomic Layer Deposited $\mathrm{ZrO}_{2}$ Coating to Enhance the Electrochemical Performance of $\mathrm{Li}_{4} \mathrm{Ti}_{5} \mathrm{O}_{12}$ as an Anode Material. Electrochim. Acta 2013, 93, 195201.

(30) H, Y.; Yu, X.; Wang, Y.; Li, H.; Huang. Alumina-Coated Patterned Amorphous Silicon as the Anode for a Lithium-Ion Battery with High Coulombic Efficiency. Adv. Mater. 2011, 23, 4938-4941.

(31) Xiao, X.; Lu, P.; Ahn, D. Ultrathin Multifunctional Oxide Coatings for Lithium Ion Batteries. Adv. Mater. 2011, 23, 3911-3915.

(32) Riely, L. A.; Cavanagh, A. S.; George, S. M.; Jung, Y. S.; Yan, Y.; Lee, S.-H.; Dillon, A. C. Conformal Surface Coatings to Enhance High Volume Expansion Li-Ion Anode Materials. ChemPhysChem 2010, 11, 2124-2130.

(33) Meng, X.; Yang, X.-Q.; Sun, X. Emerging Applications of Atomic Layer Deposition for Lithium-Ion Battery Studies. Adv. Mater. 2012, 24, 3589-3615.

(34) Knoops, H. C. M.; Donders, M. E.; van de Sanden, M. C. M.; Notten, P. H. L.; Kessels, W. M. M. Atomic Layer Deposition for Nanostructured Li-Ion Batteries. J. Vac. Sci. Technol., A 2012, 30, 010801.

(35) Putkonen, M.; Aaltonen, T.; Alnes, M.; Sajavaara, T.; Nilsen, O.; Fjellvåg, H. Atomic Layer Deposition of Lithium Containing Thin Films. J. Mater. Chem. 2009, 19, 8767-8771.

(36) Aaltonen, T.; Alnes, M.; Nilsen, O.; Costelle, L.; Fjellvåg, H. Lanthanum Titanate and Lithium Lanthanum Titanate Thin Films Grown by Atomic Layer Deposition. J. Mater. Chem. 2010, 20, 28772881.

(37) Aaltonen, T.; Nilsen, O.; Magrasó, A.; Fjellvåg, H. Atomic Layer Deposition of $\mathrm{Li}_{2} \mathrm{O}-\mathrm{Al}_{2} \mathrm{O}_{3}$ Thin Films. Chem. Mater. 2011, 23, 46694675.

(38) Hämäläinen, J.; Holopainen, J.; Munnik, F.; Hatanpää, T.; Heikkilä, M.; Ritala, M.; Leskelä, M. Lithium Phosphate Thin Films Grown by Atomic Layer Deposition. J. Electrochem. Soc. 2012, 159, A259-A263.

(39) Hämäläinen, J.; Munnik, F.; Hatanpää, T.; Holopainen, J.; Ritala, M.; Leskelä, M. Study of Amorphous Lithium Silicate Thin Films Grown by Atomic Layer Deposition. J. Vac. Sci. Technol., A 2012, 30, 01A106.

(40) Østreng, E.; Vajeeston, P.; Nilsen, O.; Fjellvåg, H. Atomic Layer Deposition of Lithium Nitride and Carbonate Using Lithium Silylamide. RSC Adv. 2012, 2, 6315-6322.
(41) Comstock, D. J.; Elam, J. W. Mechanistic Study of Lithium Aluminum Oxide Atomic Layer Deposition. J. Phys. Chem. C 2013, $117,1677-1683$.

(42) Glass, A. M.; Nassau, K.; Negran, T. J. Ionic Conductivity of Quenched Alkali Niobate and Tantalate Glasses. J. Appl. Phys. 1978, 49, 4808-4811.

(43) Li, Z.; Chen, X.; Hu, X. The Preparation of Ionic Conductance of Nano-Amorphous $\mathrm{Li}_{x} \mathrm{TaO}_{y}$ Thin Film. J. Phys. D: Appl. Phys. 1996, 29, 2740-2744.

(44) Kukli, K.; Ritala, M.; Leskelä, M. Atomic Layer Epitaxy Growth of Tantalum Oxide Thin Films from $\mathrm{Ta}\left(\mathrm{OC}_{2} \mathrm{H}_{5}\right)_{5}$ and $\mathrm{H}_{2} \mathrm{O}$. J. Electrochem. Soc. 1995, 142, 1670-1675.

(45) Cavanagh, A. S.; Lee, Y.; Yoon, B.; George, S. M. Atomic Layer Deposition of $\mathrm{LiOH}$ and $\mathrm{Li}_{2} \mathrm{CO}_{3}$ Using Lithium t-Butoxide as the Lithium Source. ECS Trans. 2010, 33, 223-229.

(46) Kukli, K.; Aarik, J.; Aidla, A.; Siimon, H.; Ritala, M.; Leskelä, M. In Situ Study of Atomic Layer Epitaxy Growth of Tantalum Oxide Thin Films from $\mathrm{Ta}\left(\mathrm{OC}_{2} \mathrm{H}_{5}\right)_{5}$ and $\mathrm{H}_{2} \mathrm{O}$. Appl. Surf. Sci. 1997, 112, 236-242.

(47) Nilsen, O.; Rauwel, E.; Fjellvåg, H.; Kjekshus, A. Growth of $\mathrm{La}_{1-x} \mathrm{Ca}_{x} \mathrm{MnO}_{3}$ Thin Films by Atomic Layer Deposition. J. Mater. Chem. 2007, 17, 1466-1475.

(48) Gaultois, M. W.; Grosvenor, A. P. XANES and XPS Investigations of the Local Structure and Final-State Effects in Amorphous Metal Silicates: $\left(\mathrm{ZrO}_{2}\right)_{x}\left(\mathrm{TiO}_{2}\right)_{y}\left(\mathrm{SiO}_{2}\right)_{1-x-y}$. Phys. Chem. Chem. Phys. 2012, 14, 205-217.

(49) Yang, S.; Wang, D.; Liang, G.; Yiu, Y. M.; Wang, J.; Liu, L.; Sun, X.; Sham, T.-K. Soft X-Ray XANES Studies of Various Phases Related to $\mathrm{LiFePO}_{4}$ Based Cathode Materials. Energy Environ. Sci. 2012, 5, $7007-7016$

(50) Kim, T. W.; Hur, S. G.; Han, A. R.; Hwang, S.-J.; Choy, J.-H. Effect of Bond Covalency on the Lattice Stability and Fatigue Behavior of Ferroelectric Bismuth Transition-Metal Oxides. J. Phys. Chem. C 2008, 112, 3434-3438.

(51) Hu, Y. F.; Xu, R. K.; Dynes, J. J.; Blyth, R. I. R.; Yu, G.; Kozak, L. M.; Huang, P. M. Coordination Nature of Aluminum (Oxy)hydroxides Formed Under the Influence of Tannic Acid Studied by X-Ray Absorption Spectroscopy. Geochim. Cosmochim. Acta 2008, 72, 19591969.

(52) Liu, J.; Tang, Y.; Xiao, B.; Sham, T.-K.; Li, R.; Sun, X. Atomic Layer Deposited Aluminum Phosphate Thin Films on N-Doped CNTs. RSC Adv. 2013, 3, 4492-4495.

(53) Gitmans, F.; Sitar, Z.; Günter, P. Growth of Tantalum Oxide and Lithium Tantalate Thin Films by Molecular Beam Epitaxy. Vacuum 1995, 46, 939-942.

(54) Atanassova, E.; Tyuliev, G.; Paskaleva, A.; Spassov, D.; Kostov, K. XPS Study of $\mathrm{N}_{2}$ Annealing Effect on Thermal $\mathrm{Ta}_{2} \mathrm{O}_{5}$ Layers on $\mathrm{Si}$. Appl. Surf. Sci. 2004, 225, 86-99.

(55) Miikkulainen, V.; Nilsen, O.; Laitinen, M.; Sajavaara, T.; Fjellvåg, $\mathrm{H}$. Atomic Layer Deposition of $\mathrm{Li}_{x} \mathrm{Ti}_{y} \mathrm{O}_{z}$ Thin Films. RSC Adv. 2013, 3, 7537-7542.

(56) Glass, A. M.; Nassau, K. Lithium Ion Conduction in Rapidly Quenched $\mathrm{Li}_{2} \mathrm{O}-\mathrm{Al}_{2} \mathrm{O}_{3}, \mathrm{Li}_{2} \mathrm{O}-\mathrm{Ga}_{2} \mathrm{O}_{3}$, and $\mathrm{Li}_{2} \mathrm{O}-\mathrm{Bi}_{2} \mathrm{O}_{3}$ Glasses. J. Appl. Phys. 1980, 51, 3756-3761.

(57) Huanosta, A.; West, A. R. The Electrical Properties of Ferroelectric $\mathrm{LiTaO}_{3}$ and Its Solid Solutions. J. Appl. Phys. 1987, 61, $5386-5391$

(58) Murugan, R.; Thangadurai, V.; Weppner, W. Fast Lithium Ion Conduction in Garnet-Type $\mathrm{Li}_{7} \mathrm{La}_{3} \mathrm{Zr}_{2} \mathrm{O}_{12}$. Angew. Chem. Int. Ed. 2007, 46, 7778-7781.

(59) Goodenough, J. B. Solid Electrolytes. Pure Appl. Chem. 1995, 67, 931-938.

(60) West, A. R. Solid Electrolytes. Ber. Bunsenges. Phys. Chem. 1989, 93, 1235-1241.

(61) Takada, K. Progress and Prospective of Solid-State Lithium Batteries. Acta Mater. 2013, 61, 759-770.

(62) Thangadurai, V.; Weppner, W. Recent Progress in Solid Oxide and Lithium Ion Conducting Electrolytes Research. Ionics 2006, 12, $81-92$. 